\title{
A Review of 3D Food Printing Technology
}

\author{
Paphakorn Pitayachaval ${ }^{1}$, Nattawut Sanklong ${ }^{1}$ and Anantapoom Thongrak ${ }^{1}$ \\ ${ }^{1}$ School of Industrial Engineering, Institute of Engineering, Suranaree University of Technology, Thailand
}

\begin{abstract}
The additive manufacturing technology has been applied to directly construct physical model from 3D model without mold and die. Several industries utilize this technology to manufacture a complicated part such as automobile, aerospace including food industry. The advantage 3D food printing are ability to produce complex food model and ability to design unique pattern. A 3D food printing technique is composed of an extrusion-based printing, binder jetting and inkjet printing. The food materials such as sugar, chocolate, and cheese are used to create designed shape based on layer-by-layer. This paper presents a review of 3D food printing techniques. This review is to categorize, printability, productivity, properties of material and mechanism of 3D food printing techniques, as well as to provide the direction of future development.
\end{abstract}

\section{Introduction}

A three-dimensional (3D) printing, called additive manufacturing (AM), established since 1980s, have been developed and applied in variety applications for many industries. AM crates model by adding material layer by layer from a computerized 3D solid model. An advantage of AM is to construct a complexity model without mold and die, fixtures, cutting tools and coolants. The application of construction AM model have been wildly used in many fields of industry such as automotive, architecture, medical and fashion design. Including, food manufacturing also applies this technology to fabricate food design. However, a sustainable nutrition and food security are the global agenda and key themes, which are considered during, apply 3D food printing. There are several techniques to construct $3 \mathrm{D}$ food printing that are an extrusion-based printing, binder jetting and inkjet printing. This paper aims to review those techniques based on a printability, productivity, properties of material, effect parameters and mechanism of 3D food printing techniques. Including, the advantages and disadvantages of those techniques are also established.[17]

\section{Category of 3D Food Printing Technique}

The 3D food printing technique has been classified into three categories that are an extrusion-based printing, binder jetting and inkjet printing, as shown in figure 1 .

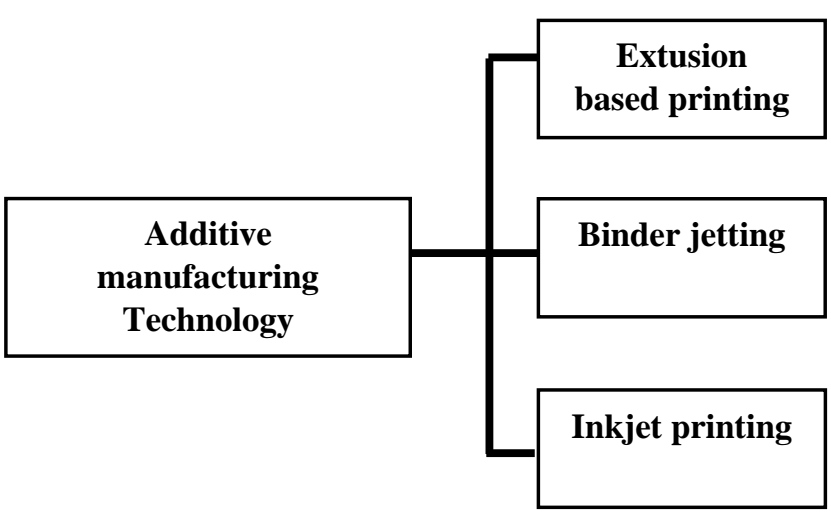

Figure 1. Classified of 3D printing technique

\subsection{Extrusion-based printing}

The extrusion-based printing constructs food model by extruding food through a nozzle with a constant pressure. This technique is similar to a conventional Fused Deposition Modeling (FDM). However, the starting material of extrusion-based printing can be both solid and paste (soft) with low viscosity, while the starting material of FDM is wire. In this extrusion-based printing process, material is loaded in extruder (cylinder) before it is extruded through nozzle by ram pressure to create food shape layer - by - layer, as shown in figure 2 . The example of food, fabricated via this technique, are dough meat paste and cheese. Lipton, et al. (2010) tested a variety of recipes to print sugar cookies. The result shown that the variation of ingredient concentration effected to fabricate food model especially ratio of butter, yolk and sugar. Therefore, transglutaminase and bacon fat were added to simplify model fabrication. Moreover, Fanli 
Yang, et al.[8] applied extrusion at room temperature to print lemon juice gel using the extruder conveying screw, as shown in figure 3. After that, L. Wang, et al. [9] conducted the experiment via the similar system with Fanli Yang, et al. [8] to print fish surimi gel. The results shown that the nozzle diameter, the nozzle movement speed and the extrusion rate affect the quality of 3D food printing, excluding the nozzle height. To print solid stating material, M. Lanaro et al. [10] investigated on melting extrusion for printing complex chocolate model based on machine design, including mechanism design. The results shown that there are two important areas of design in which (1) designing the extruder assembly to be as rigid as possible, thereby reducing flexion and enabling more accurate deposition of chocolate and (2) improving the design of active cooling system to quench the chocolate at lower temperatures, as shown in figure 4.

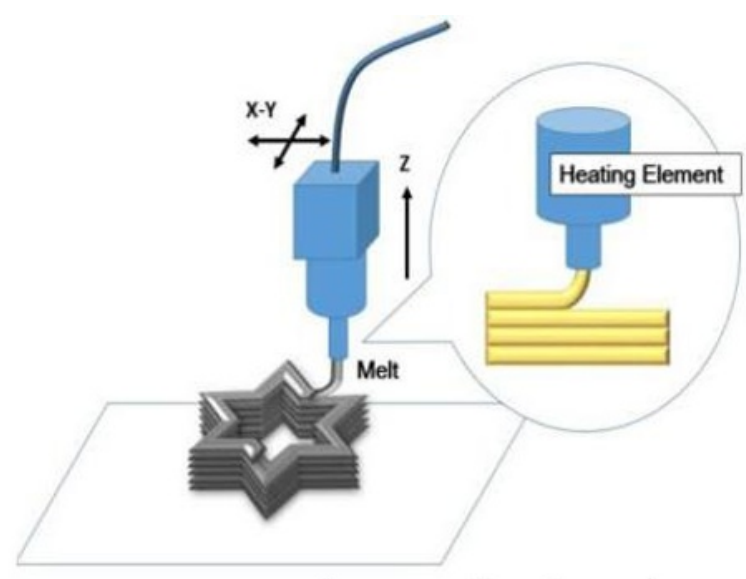

Figure 2. Extrusion-based printing (Peng, Zhou, Jerry, Hong, and Annette, 2015)

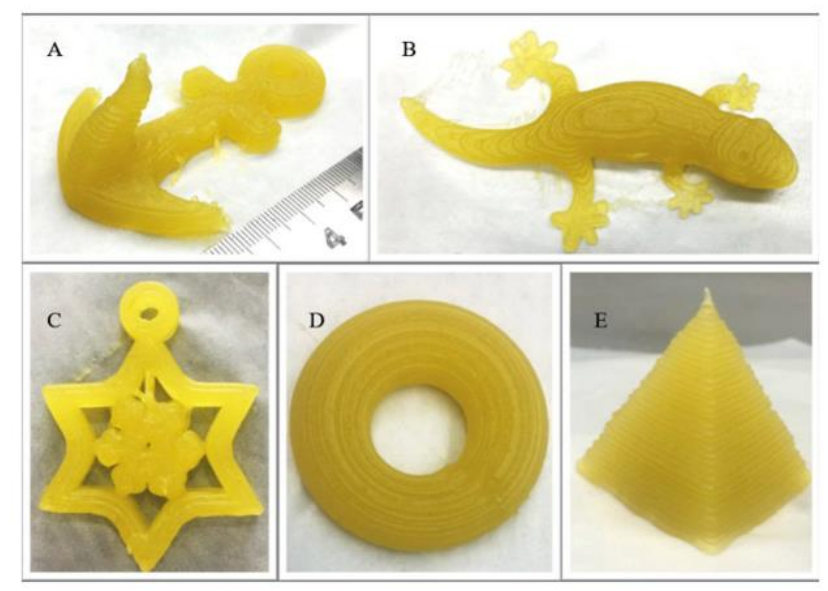

Figure 3. The 3D printing technique based on soft-material (A. Anchor, B. Gecko, C. Snowflake, D. Ring, E. Tetrahedron). L. Wang et al. (2018)

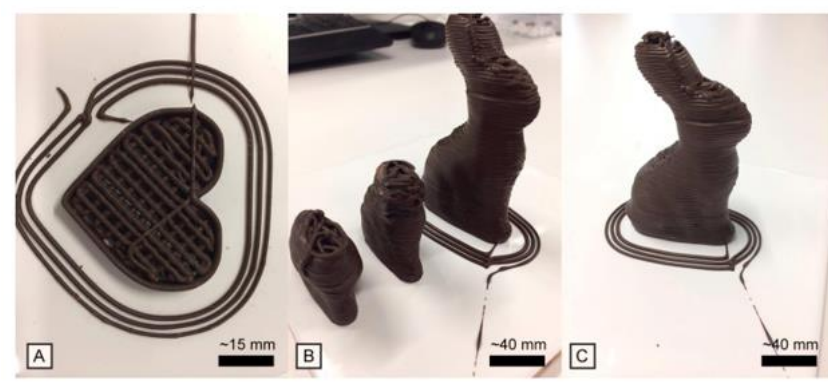

Figure 4. The 3D printing technique based on melting extrusion. (Lanaro, et al. 2017)

\subsection{Inkjet Printing (IJP)}

The inkjet printing dispenses a material stream of droplets from a thermal head to certain regions for creating the surface filling or decorating on food surfaces, such as cookie, cake, and pizza, as shown in figure 5. This process generally operates by using thermal or piezoelectric heads. In a thermal inkjet printer, the print head is electrically heated to establish pulses of pressure that push droplets from the nozzle [11]. There are two types of inkjet printing methods: a continuous jet printing and a drop-on-demand printing. For the continuous jet printer, an ink is ejected continuously through a piezoelectric crystal by vibrating with a constant frequency. In order to obtain a desired flow ability of the ink, some conductive agents had been added. For a dropon-demand printer, a valve is a controller ink to eject out from heads under designed pressure. The printing rates of drop-on-demand systems are generally slower than the continuous jet systems, beside the resolution and precision of produced images are higher [12]. The inkjet printer normally handle low viscosity materials; therefore, it does not find application on the construction of complex food structure. Typical deposited materials are chocolate, liquid dough, sugar icing, meat paste, cheese, jams, gels and etc[11].

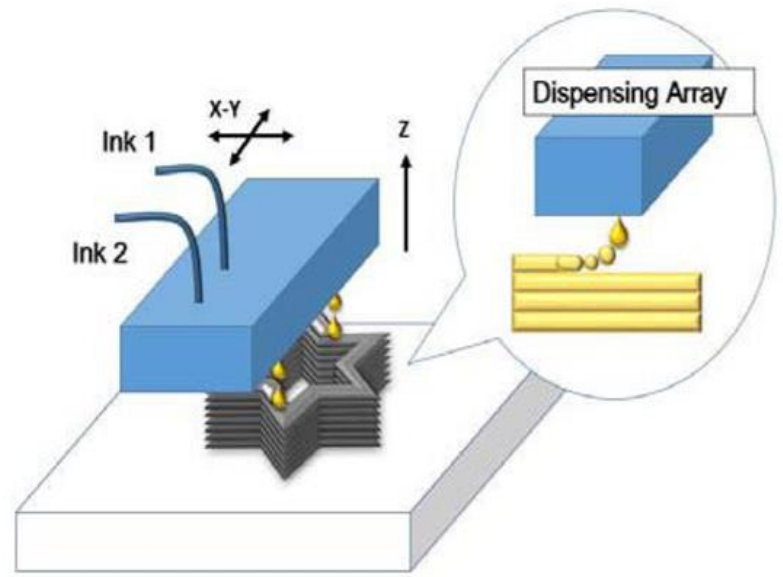

Figure 5. Inkjet printing (IJP) (Peng, Zhou, Jerry, Hong, and Annette, 2015) 


\subsection{Binder jetting}

The binder jetting, which is an additive manufacturing technology, constructs model by using a binder to selectively bond layers of powders. In this process, small droplets of binder with diameters less than $100 \mu \mathrm{m}$ are successively deposited on to the powder bed surface, which those are a drop-on-demand print head based on rater scanning pattern. After deposition of the liquid binder, the entire surface of the powder bed is exposed to a fixed amount of heat, which commonly use a heat lamp, for establishing an appropriated mechanical strength via partially cured binder within the generated layer to withstand the shear and gravitational compressive forces involved in the spreading and printing of subsequent layers. These steps are repeated for each layer until the whole feature was completed [13].

For binder jetting process, properties of powdered material and binder are important to the successful fabrication of parts. The binder has to be suitable low viscosity in which surface tension and ink density are suitable properties to prevent spreading from nozzles [14]. S. Holland, et al. were developed food grade inks possessed the necessary properties to be successfully ink jet printed in a Fujifilm Dimatix printer, as shown in figure $6 .[15]$.

Table 1. List of printability 3D printing technology applied for food design.

\begin{tabular}{|c|c|c|c|}
\hline & \multicolumn{3}{|c|}{ Category } \\
\hline & $\begin{array}{c}\text { Extrusion } \\
\text {-based printing }\end{array}$ & Binder jetting & Inkjet printing \\
\hline Principle & Extrusion and deposition & $\begin{array}{l}\text { Powder binding and } \\
\text { binder drop-on demand } \\
\text { deposition }\end{array}$ & $\begin{array}{l}\text { Drop-on-demand } \\
\text { deposition and } \\
\text { Continuous jet printing }\end{array}$ \\
\hline Material & $\begin{array}{l}\text { Solid-based, } \\
\text { Paste material }\end{array}$ & $\begin{array}{l}\text { Liquid-based, } \\
\text { Powder-based }\end{array}$ & $\begin{array}{l}\text { Liquid-based, } \\
\text { low viscosity material }\end{array}$ \\
\hline Processing factor & $\begin{array}{l}\text {-Printing head height } \\
\text {-Nozzle diameter } \\
\text {-Printing rate } \\
\text {-Nozzle movement rate }\end{array}$ & $\begin{array}{l}\text {-Printing head types } \\
\text {-Printing rate } \\
\text {-Nozzle diameter } \\
\text {-Layer thickness }\end{array}$ & $\begin{array}{l}\text {-Temperature in print } \\
\text { head } \\
\text {-Printing rate } \\
\text {-Nozzle diameter } \\
\text {-Printing head height }\end{array}$ \\
\hline Advantage & $\begin{array}{l}\text {-Low cost of the entry- } \\
\text { level machines } \\
\text {-A variety of raw } \\
\text { materials are available } \\
\text {-Easy to customize }\end{array}$ & $\begin{array}{l}\text {-Large number of } \\
\text { potential materials } \\
\text {-Very high production } \\
\text { speed } \\
\text {-Support structures are } \\
\text { included automatically in } \\
\text { layer fabrication } \\
\text {-Low-imaging specific } \\
\text { energy } \\
\text {-Complex 3D food } \\
\text { fabrication }\end{array}$ & $\begin{array}{l}\text {-No waste of model } \\
\text { material } \\
\text {-High resolution and } \\
\text { accuracy } \\
\text {-Multiple materials and } \\
\text { multiple colors } \\
\text {-Fast fabrication }\end{array}$ \\
\hline Disadvantage & $\begin{array}{l}\text {-Low level of precision } \\
\text { and long build time } \\
\text {-Unable to build sharp } \\
\text { external corners } \\
\text {-Anisotropic nature of a } \\
\text { printed part } \\
\text {-Difficult to hold 3D } \\
\text { structures in post- } \\
\text { procesing }\end{array}$ & $\begin{array}{l}\text {-Rough or grainy } \\
\text { appearance } \\
\text {-Post-processing required } \\
\text { to remove moisture or } \\
\text { improve strength } \\
\text {-Limited material } \\
\text {-Less nutritious products }\end{array}$ & $\begin{array}{l}\text {-Post-processing may } \\
\text { damage thin and small } \\
\text { features } \\
\text {-Support materials cannot } \\
\text { by recycled thus wasted } \\
\text {-Simple food design } \\
\text {-Only for surface filling } \\
\text { or image decoration }\end{array}$ \\
\hline Application & $\begin{array}{l}\text { Chocolate, Confection, } \\
\text { Decorations made of } \\
\text { sugar, Candies }\end{array}$ & $\begin{array}{l}\text { Chocolate, Pizza (Powder } \\
\text { form), } \\
\text { Fake food }\end{array}$ & $\begin{array}{l}\text { Chocolate, Liquid dough, } \\
\text { sugar icing, meat paste, } \\
\text { cheese, jams, gels }\end{array}$ \\
\hline Machine & $\begin{array}{l}\text { Choc Creator, } \\
\text { AIBOULLY Chocolate, } \\
\text { Createbot 3D Food } \\
\end{array}$ & Chefjet, Fujifilm Dimatix & $\begin{array}{l}\text { Foodjet, Filament six- } \\
\text { head 3D }\end{array}$ \\
\hline Company & $\begin{array}{l}\text { Chocedge, AIBOULLY, } \\
\text { Createbot }\end{array}$ & $\begin{array}{l}\text { 3D systems, Fujifilm } \\
\text { Dimatix }\end{array}$ & $\begin{array}{l}\text { De Grood Innovations, } \\
\text { TNO }\end{array}$ \\
\hline
\end{tabular}




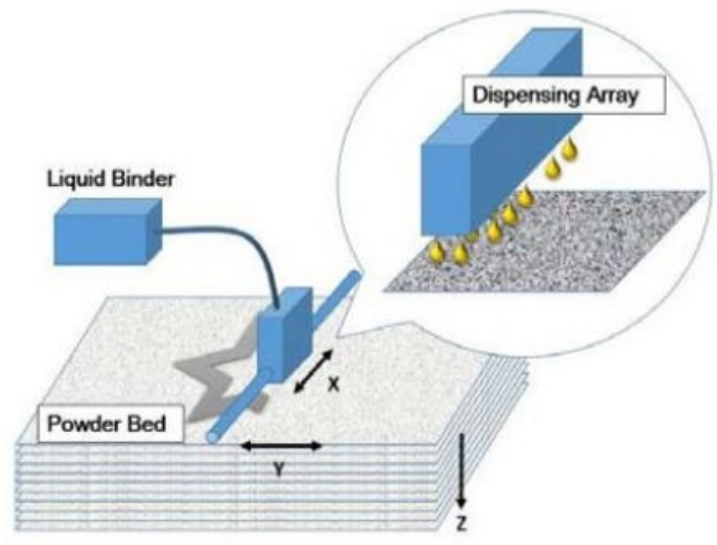

Figure 6. Binder jetting (IJP) (Peng, Zhou, Jerry, Hong, and Annette, 2015)

\section{Summary}

The Additive manufacturing technologies have been wildly used in several industries including food manufacturing to crate the fantastic food shape. There are variety techniques such as extrusion-based printing, binder jetting and inkjet printing.

In extrusion-based printing, food materials are extruded through nozzle to create food designed shape layer - by layer. Based on the low viscosity property of material, the suitable materials in this technique are solid-based and paste material. The processing factor of this technique are printing head height, nozzle diameter and nozzle movement rate. The advantage of this technique are the low cost of the entry-level machines, a variety of raw materials are available and easy to customize while the low level of precision and long build time are the disadvantage of extrusion-based printing.

In inkjet printing, food materials are loaded in print head then they is electrically heated to establish pulses of pressure that push droplets from the nozzle. There are two types of printing; a jet printing and a drop-ondemand printing. By using the low viscosity property of material, the suitable materials in this technique is liquidbased. The processing factor of this technique are temperature print head, nozzle diameter and printing rate. The advantages of this technique are high resolution, accuracy and multiple materials while post-processing may damage thin and small features, which is disadvantage of inkjet printing.

In binder jetting, food materials are successively deposited on to the powder bed surface through nozzle. Based on the low viscosity, surface tension and ink density, the suitable material in this technique are liquidbased, powder-based. The processing factor of this technique are printing head type, nozzle diameter and layer thickness. The advantage of this technique are the very high production speed, support structures are included automatically in layer fabrication while the disadvantage are rough or grainy appearance, post- processing required to remove moisture or improve strength of binder jetting.

\section{References}

1. M. Annoni , H. Gilberti , M. Strano. (2016). Feasibility Study of an Extrusion-based Direct Metal Additive Manufacturing Technique. 44th Proceedings of the North American Manufacturing Research Institution of SME http:// www.sme.org/namrc. Volume 5, 2016, Pages 916927.

2. Shannon E. Bakarich , R. Gorkin III , R. Gately, S. Naficy, Marc in het Panhuis, Geoffrey M. Spinks. (2017). 3D printing of tough hydrogel composites with spatially varying materials properties. Additive Manufacturing 14 (2017) 24-30.

3. Teresa F. Wegrzyn , Matt Golding, Richard H. Archer. (2012). Food Layered Manufacture: A new process for constructing solid foods. Trends in Food Science \& Technology 27 (2012) 66-72.

4. J.Y. Lee, Jia An, Chee Kai Chua. (2017). Fundamentals and applications of 3D printing for novel materials. Applied Materials Today 7 (2017) 120-133.

5. Nguyen, Tuan C. "Hungry? A Startup Wants You to 3D Print Your Next Meal." http://www.smithsonianmag.com/innovation/hungrya-startup-wants-you-to-3d-print-your-next-meal180947702/ (accessed September 18, 2017).

6. Jayakuma, Amrita. "Home-Baked Idea? Nasa mulls 3D printers for food replication." The Guardian.https://www.theguardian.com/technology/2 013/jun/04/nasa-3d-printer-space-food (accessed September 18, 2017).

7. New technology often builds on old technology. Understanding how the present printers work and discovering their advantages and disadvantages may help people create more useful food printers in the future.

8. F. Yang, M. Zhang, B. Bhandari, Y. Liud. (2018). Investigation on lemon juice gel as food material for 3D printing and optimization of printing parameters. LWT - Food Science and Technology Volume 87, January 2018, Pages 67-76

9. L. Wang, M. Zhanga, B. Bhandari, C. Yangd. (2018). Investigation on fish surimi gel as promising food material for 3D printing. Journal of Food Engineering Volume 220, March 2018, Pages 101108

10. M. Lanar, David P.Forrestal, S Scheurer, Damien J.Slinger, S. Liao, S. K.Powell, Maria A.Woodruff. (2017). 3D printing complex chocolate objects: Platform design, optimization and evaluation. Journal of Food Engineering Volume 215, December 2017, Pages 13-22

11. Fernanda C.Godoi, Sangeeta Prakash, Bhesh R.Bhandari. (2016). 3D printing technologies applied for food design: Status and prospects. Journal of Food Engineering Volume 179, June 2016, Pages 4454 
12. Z. Liu, M. Zhang, B. Bhandari, Y. Wang. (2017). 3D printing: Printing precision and application in food sector. Trends in Food Science \& Technology Volume 69, Part A, November 2017, Pages 83-94

13. H. Miyanaji, N. Momenzadeh, L. Yanga. (2018). Effect of printing speed on quality of printed parts in Binder Jetting Process. Additive Manufacturing Volume 20, March 2018, Pages 1-10

14. J. Sun, Z. Peng, W. Zhou, Jerry Y.H.Fuh, G. Soon Hong, A. Chiu. (2015). A Review on 3D Printing for
Customized Food Fabrication. Procedia Manufacturing Volume 1, 2015, Pages 308-319

15. S. Holland, T. Foster, W. MaNaughtan, C. Tuck. (2018). Design and characterisation of food grade powders and inks for microstructure control using 3D printing. Journal of Food Engineering Volume 220, March 2018, Pages 12-19 